\title{
Analysis of metal transfer and weld geometry in hot-wire GTAW with indirect resistive heating
}

\author{
T. Ungethüm ${ }^{1} \cdot$ E. Spaniol ${ }^{1} \cdot$ M. Hertel ${ }^{1} \cdot$ U. Füssel $^{1}$
}

Received: 4 December 2019 / Accepted: 28 August 2020 / Published online: 3 September 2020

(C) The Author(s) 2020

\begin{abstract}
In this publication, the different metal transfer modes of a hot-wire GTAW process with indirect resistive preheating of the wire are presented. The hot-wire GTAW process is characterized by an additional preheating unit that is used to heat the wire before it reaches the melt pool. Thus, to preheat the wire, the contact between the melt pool and the wire is not necessary. In order to examine the metal transfer of the wire, deposition welds are analysed using a high-speed camera with a laser light source as well as a data acquisition unit. The presented results comprise the impact analysis of the GTAW current, the hot-wire current, the wire feeding rate, the wire feeding angle as well as the wire feeding direction. The observed metal transfer modes can be characterized as either a constant melting bridge $(\mathrm{cmb})$ between the wire and the melt pool or a recurring melting bridge (rmb). The analysis also reveals that the influence of the process parameters and thus the metal transfer mode on the bead properties is only marginal.
\end{abstract}

Keywords WAAM $\cdot$ GTAW $\cdot$ TIG $\cdot$ Hot-wire $\cdot$ Metal transfer

\section{Introduction}

The demands placed on industrial production, especially with regard to variant diversity and development time, are constantly growing. In order to respond better to customer wishes, companies have to reduce the development time for products on the one hand but on the other hand also need to be able to produce smaller batches and individual parts economically [1]. In the industrial production, the individual semi-finished products are usually produced by processes such as casting, extrusion or forging, subsequently processed further by machining and finally joined to form an assembly using various joining processes. When using additive manufacturing, on the other hand, the components are produced by building up layers of material and are then subjected to final processing. This type of component construction offers a number of advantages over conventional manufacturing methods. Due to

Recommended for publication by Commission XII - Arc Welding Processes and Production Systems

T. Ungethüm

tim.ungethuem@tu-dresden.de

1 Faculty of Mechanical Science and Engineering, Institute of Manufacturing Technology, Chair of Joining Technology and Assembly, TU-Dresden, Dresden, Germany the layered structure, very sophisticated geometries with complicated undercuts and cavities, such as integrated cooling channels, can be realized [2]. In addition, the component can be manufactured near-net-shape, so that a considerable portion of the machining volume can be saved on milled parts, thus significantly reducing manufacturing time as well as costs. In recent years, a large number of processes have been developed for additive manufacturing of metal parts. At present, the most commonly used processes are those in which a powder bed is melted by an energy source (e.g., electron beam melting or selective laser sintering) [3, 4]. However, arc-based processes with wire as a filler material are becoming increasingly important. Due to the low investment costs and high possible melting rates, arc-based processes are mainly used for the production of large-volume components. The disadvantage of these processes is the increased post-processing effort. For arc-based additive production, processes that are already established for joint welding, such as gas metal arc welding (GMAW) and gas tungsten arc welding (GTAW), are used. However, since these processes were developed for welding tasks, they have process-related disadvantages for the application in additive manufacturing. Examples are a dependency of weld formation on the welding direction, if a filler wire is used, or an extensive heat input into the component. As a result, the arc-based additive processes have so far only been used occasionally in the industrial sector. 
Fig. 1 Schematic illustration of the TIG hot-wire process with indirect resistive preheating of the wire

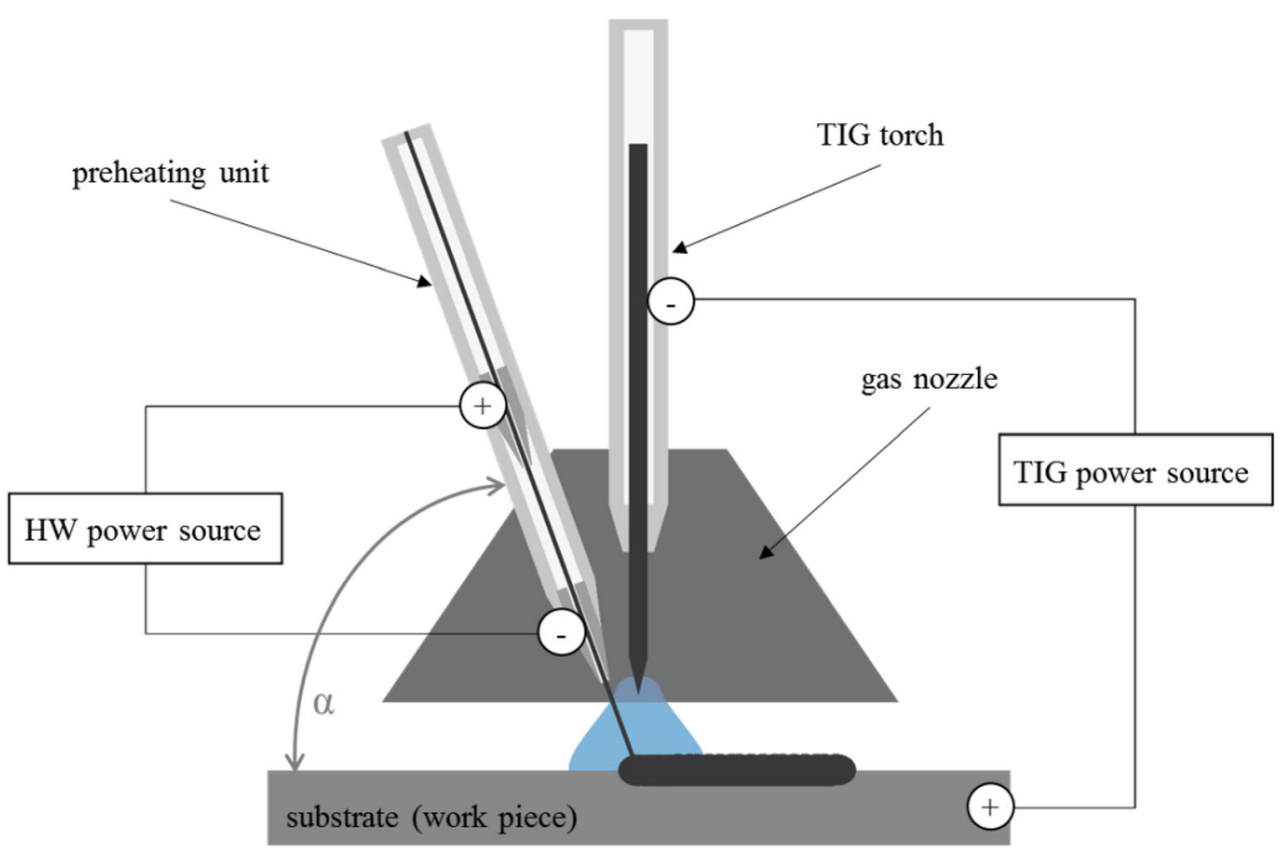

\section{GTAW hot-wire processes}

GTAW hot-wire welding was developed by Manz and Saenger in 1964 [5, 6]. For this method, a TIG process is combined with a wire feed, and the wire is additionally preheated. This preheating is realized via an electrical potential between the wire feed and the workpiece. When the contact between the wire and the melt pool (workpiece) is established, the circuit is closed and resistance heating occurs, resulting in a sharp increase in the temperature of the wire. This greatly reduces the heat required for the complete melting of the wire by the arc and increases the energy input into the component. Therefore, it is possible to increase the deposition rate and thus productivity. The resistive heating only takes place as long as the wire is in contact with the melt pool and the circuit is thus closed. If the melt bridge is dissolved, the resistance heating is interrupted so that process instabilities may occur. As a result of the interrupted heating of the wire, conventional GTAW hot-wire processes have a very limited process window [7]. For a high process stability, a sustained connection between the wire and the melt pool is necessary. Therefore, the metal transfer in conventional hot-wire processes can be characterized as a continuous melting bridge [8]. Furthermore, in conventional hot-wire processes, a deflection of the arc also occurs as a result of arc blow [7]. This effect has a strong, often negative, influence on the process. In order to reduce the influence of the arc blow and increase process stability as well as productivity, Hori et al. [7] implemented pulsing of the hot-wire current. During the phases of the pulse current where no current is flowing, there is also no arc blow effect. With the use of pulsed hot-wire current, it is possible to achieve very high wire feeding rates of up to $9 \mathrm{~m} / \mathrm{min}$ [9-12]. To further improve the drop separation of the wire, a mechanical oscillation of the wire has been proposed by Santangelo [13] and Henon [14].

Table 1 Experimental parameters

\begin{tabular}{ll}
\hline Welding process & GTAW hot-wire \\
\hline Welding position & PA \\
Welding type & Deposition welding \\
Welding torch inclination & $0^{\circ}$ (neutral) \\
Electrode type & Pure tungsten (green) \\
Electrode diameter & $4 \mathrm{~mm}$ \\
Electrode tip angle & $30^{\circ}$ \\
Arc length & $6 \mathrm{~mm}$ \\
Base material & S235JR \\
Filler material & Solid wire G3Si1 \\
Wire diameter & $1.2 \mathrm{~mm}$ \\
Preheating length & $30 \mathrm{~mm}$ \\
Current type hot-wire & Direct current \\
Travel speed & $5 \mathrm{~mm} / \mathrm{s}$ \\
Welding length & $50 \mathrm{~mm}$ \\
Process gas & Ar \\
Process gas volume flow & $25 \mathrm{l} / \mathrm{min}$ \\
$\mathrm{I}_{\text {TIG }}$ (reference) & $225 \mathrm{~A}$ \\
$\mathrm{I}_{\mathrm{HW}}$ (reference) & $150 \mathrm{~A}$ \\
$\mathrm{v}_{\mathrm{HW}}$ (reference) & $6.5 \mathrm{~m} / \mathrm{min}$ \\
$\alpha$ (reference) & $70^{\circ}$ \\
Feeding direction (reference) & sidefeed \\
\hline &
\end{tabular}


Fig. 2 Metal transfer for a welding current $\mathrm{I}_{\mathrm{TIG}}$ of $225 \mathrm{~A}$ (left) and $250 \mathrm{~A}$ (right)
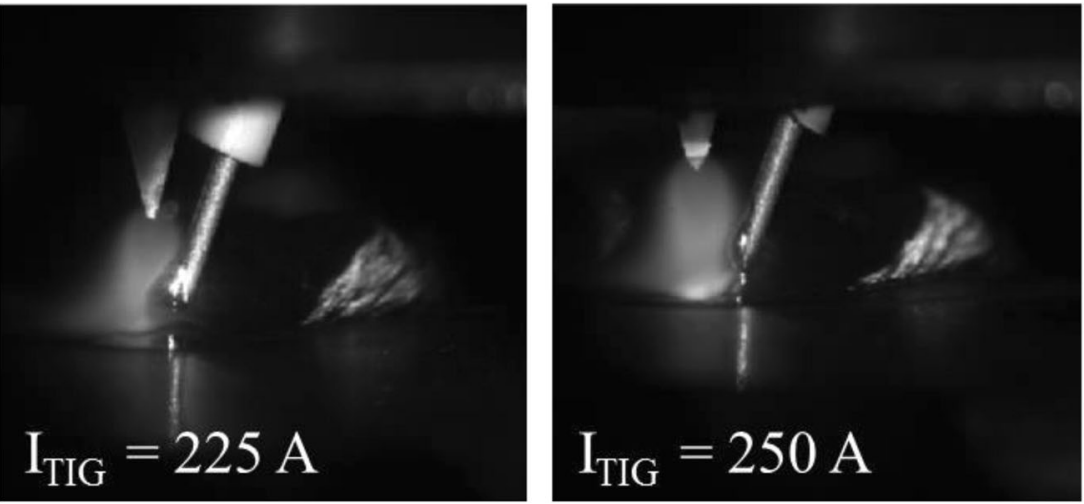

In order to compensate the described problems (small process window, arc blow) and to be able to use conventional hotwire processes for additive manufacturing, different approaches have been pursued in the previous development. Chen et al. [15] developed a process where the wire is melted using a secondary arc between the electrode and the wire. The intent is to achieve a decoupling of the melt pool generation and the melting of the filler material. The wire also is detached drop by drop and released into the molten bath by using pulse current, and the drop frequency depends on the frequency of the pulse current. In this process, the metal transfer can occur as a continuous melting bridge similar to conventional hotwire processes or as a drop-shaped detachment of the hotwire similar to that of GMAW processes [16]. This type of GTAW hot-wire process is accompanied by highly complex systems technology and process control. An economic application of this process has not yet been documented.

A further possibility of additional wire preheating has been presented by Lv et al. [17]. The filler material is preheated using a second torch. A second arc is established between the torch and the filler wire before it is fed to the molten bath. Therefore, it is possible to completely decouple the preheating from the GTAW process. This preheating process is accompanied by an increase in the complexity of the system technology. The process was developed primarily for filler materials with lower electrical resistance, such as copper or aluminium. To decouple the preheating and GTAW process, it is also possible to use inductive preheating of the filler material. For this purpose, McAninch [18] patented a process using a coil to increase the temperature of the wire by inductively heating it, shortly before it is immersed into the melt pool. Inductive preheating is associated with a more complex structure and large diameter of the wire feed unit, therefore resulting in less accessibility.

Another method to preheat filler wire without a connection to the work piece has been patented by Stol [19]. The preheating of the hot-wire is realized by resistive heating of the wire using two successive, electrically insulated contact points, which are provided within the preheating unit. A hot- wire current can be applied between these contact points, which can be flexibly adapted to the wire feed rate. Furthermore, Spaniol et al. [20] examined the use of the process for additive manufacturing. They show that the application of the process with a steep wire feeding angle leads to a direction independent component build-up and high process stability. Therefore, this process will be investigated in the context of this contribution.

From previous investigations, it can be seen that a variation of the technological and geometrical process parameters has a considerable influence on the process stability as well as the bead geometry [21]. Therefore, in the context of this contribution, the metal transfer of the process in dependence of the process parameters is examined more closely. Furthermore, the influence of the metal transfer on the inner and outer bead geometry will be determined.

\section{Experimental setup}

In Fig. 1, a schematic illustration of the GTAW hot-wire process with indirect resistive heating of the wire is shown. For the investigations, deposition welds were produced. The parameters shown in Table 1 are used for the reference process.

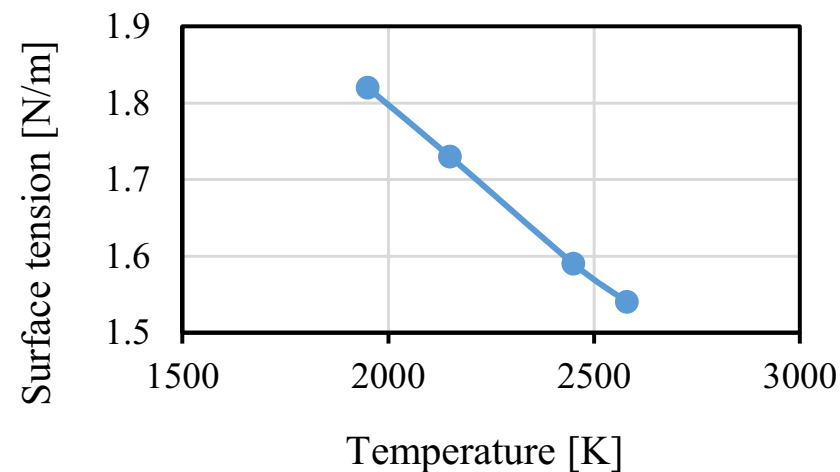

Fig. 3 Surface tension as a function of the temperature for pure iron (from [22]) 
Fig. 4 Cross sections for a welding current $\mathrm{I}_{\text {TIG }}$ of $225 \mathrm{~A}$ (left) and $250 \mathrm{~A}$ (right)
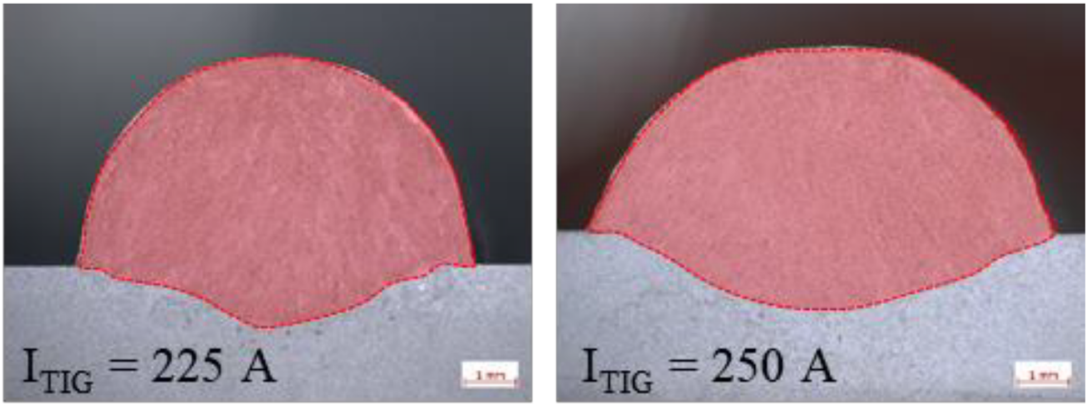

In order to investigate the influence of the technological and geometric parameters, those were varied as follows:

- $\quad$ TIG current $\left(\mathrm{I}_{\mathrm{TIG}}\right): 225 \mathrm{~A}$ and $250 \mathrm{~A}$

- Hot-wire current $\left(\mathrm{I}_{\mathrm{HW}}\right): 100-150 \mathrm{~A}$

- Wire feed rate $\left(\mathrm{v}_{\mathrm{HW}}\right): 6-8 \mathrm{~m} / \mathrm{min}$

- Wire feeding angle $(\alpha): 70^{\circ}$ and $60^{\circ}$

- Direction of wire feed: sidefeed, frontfeed, rearfeed

- Type of high-speed camera: Photron Fastcam SA4

- Distance between camera and target: $300 \mathrm{~mm}$

- Type of lens: Navitar 12x Zoom Lens System

- Type of illumination laser: Cavilux HF

- Laser wavelength: $808 \mathrm{~nm}$

- Type of optical filters: $808 \mathrm{~nm}$ and $810 \mathrm{~nm}$

- Camera sample rate: $5000 \mathrm{fps}$

- Camera shutter speed: $1 / 20000 \mathrm{~s}$

For the analysis of the process behaviour, measurements of the electrical data with a sample rate of $100 \mathrm{kHz}$ and synchronized high-speed video data with a sample rate of $5000 \mathrm{fps}$ were performed. The video recordings were performed using a non-invasive laser illumination with a wavelength of $808 \mathrm{~nm}$ and spectral-selective optical filters with a wavelength of $808 \mathrm{~nm}$ and $810 \mathrm{~nm}$, respectively.
The produced beads are subjected to an external and internal bead analysis based on DIN EN ISO 5870 [21]. The bead height and width are determined using optical 3D microscopy, the penetration depth by metallographic examinations.

\section{Results}

\subsection{Influence of the TIG current}

In this chapter, the influence of the TIG current on the metal transfer and the process behaviour is described. Figure 2 illustrates high-speed camera images of the process area for a TIG current of $225 \mathrm{~A}$ and $250 \mathrm{~A}$.

For both investigated sets of parameters, it can be seen that the wire tip is completely molten. Due to the high surface tension, these molten wire tips are only detached when a melting bridge is formed between the wire and the weld pool. The melt bridge is then dissolved and the wire tip melted again. Therefore, the occurring type of metal transfer can be described as a recurring melting bridge (rmb). The values for the surface tension of pure iron are shown in Fig. 3.

From the process pictures shown in Fig. 2, it can be seen that there are slight differences in the material transition with a $25 \mathrm{~A}$ change of the TIG current. In the process with $225 \mathrm{~A}$
Fig. 5 Metal transfer for a hotwire current $\mathrm{I}_{\mathrm{HW}}$ of $100 \mathrm{~A}$ (left) and $150 \mathrm{~A}$ (right)
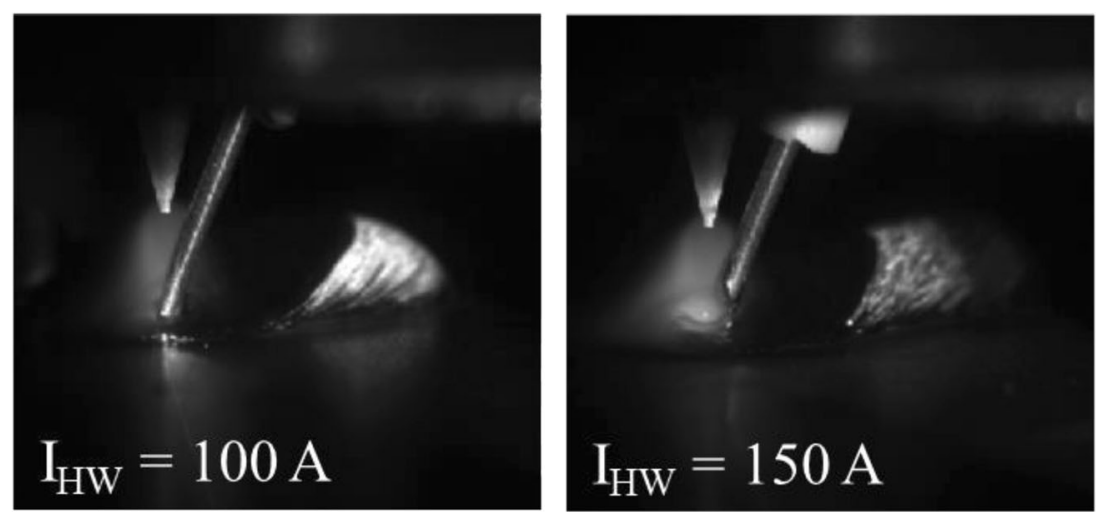


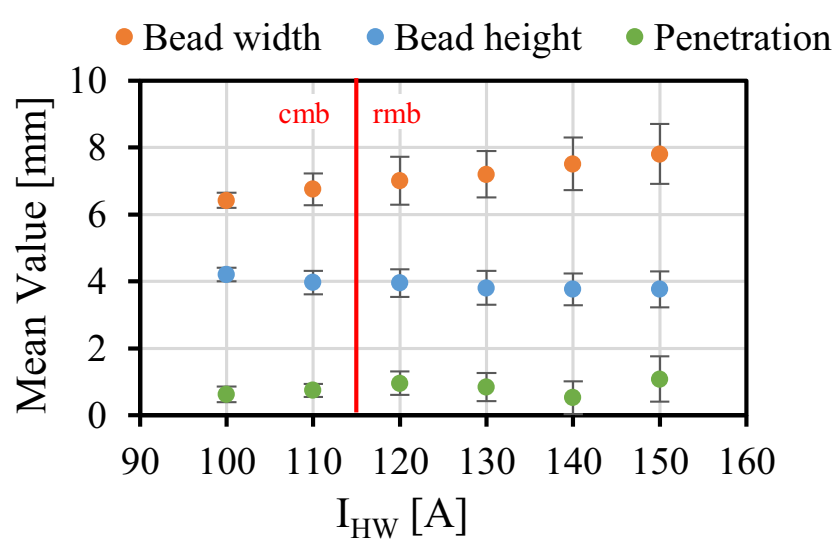

Fig. 6 Bead height, bead width and penetration for different hot-wire currents $\mathrm{I}_{\mathrm{HW}}$

TIG current, the melting process of the wire begins after it has travelled a longer distance within the arc. Additionally, the molten wire tip is larger than at $250 \mathrm{~A}$.

It can be assumed that the easier detachment of the molten material is due to a decrease of the surface tension. This decrease is caused by an increased temperature of the wire due to an increased heat input through the arc. The cross sections of the investigated welds are displayed in Fig. 4. The increased temperature and thus heat input can be derived from the penetration depth, which is $1.081 \mathrm{~mm}$ for $225 \mathrm{~A}$ and $1.517 \mathrm{~mm}$ for $250 \mathrm{~A}$, respectively. The decrease in surface tension leads to a better wetting behaviour, resulting in a contact angle of $64.5^{\circ}$ for $250 \mathrm{~A}$ and $76.7^{\circ}$ for $225 \mathrm{~A}$.

Furthermore, the arc is slightly deflected in the direction of the melting bridge when the wire establishes contact with the weld pool. This deflection is introduced immediately when the wire gets in contact with the weld pool. This indicates that the current path in the process follows the path of lower electrical resistance through the contacted filler wire rather than through the gas to the work piece. This theory is supported by the evaluation of the voltage signal of the TIG process. A reduction of the arc voltage during the build-up and an increase of this voltage during the dissolution of the melt bridge can be observed.

\subsection{Influence of the hot-wire current}

In this chapter, the influence of the hot-wire current on the metal transfer and the process behaviour is described. For this purpose, process visualizations with a hot-wire current of $100 \mathrm{~A}$ and $150 \mathrm{~A}$ are shown in Fig. 5.

It can be seen that for a hot-wire current of $100 \mathrm{~A}$, the wire is in permanent contact with the melting pool. Thus, a continuous melting bridge $(\mathrm{cmb})$ is formed. In addition, faltering movements of the filler wire are observable. An explanation for this can be seen in the fact that the temperature of the wire is too low, i.e. the wire cannot be melted immediately when it is immersed in the weld pool and is therefore touching the bottom of the weld pool. This behaviour does not impair the process stability and seam quality [23]. If the hot-wire current is increased, a recurring melting bridge between the filler wire and the weld pool with a decrease of the size of the molten wire tip can be observed. The higher the hot-wire current, the higher the frequency of the formation and dissolution of the melting bridge. This can be explained by the increased temperature
Fig. 7 Different metal transfer modes recurring melting bridge (above) and continuous melting bridge (below)

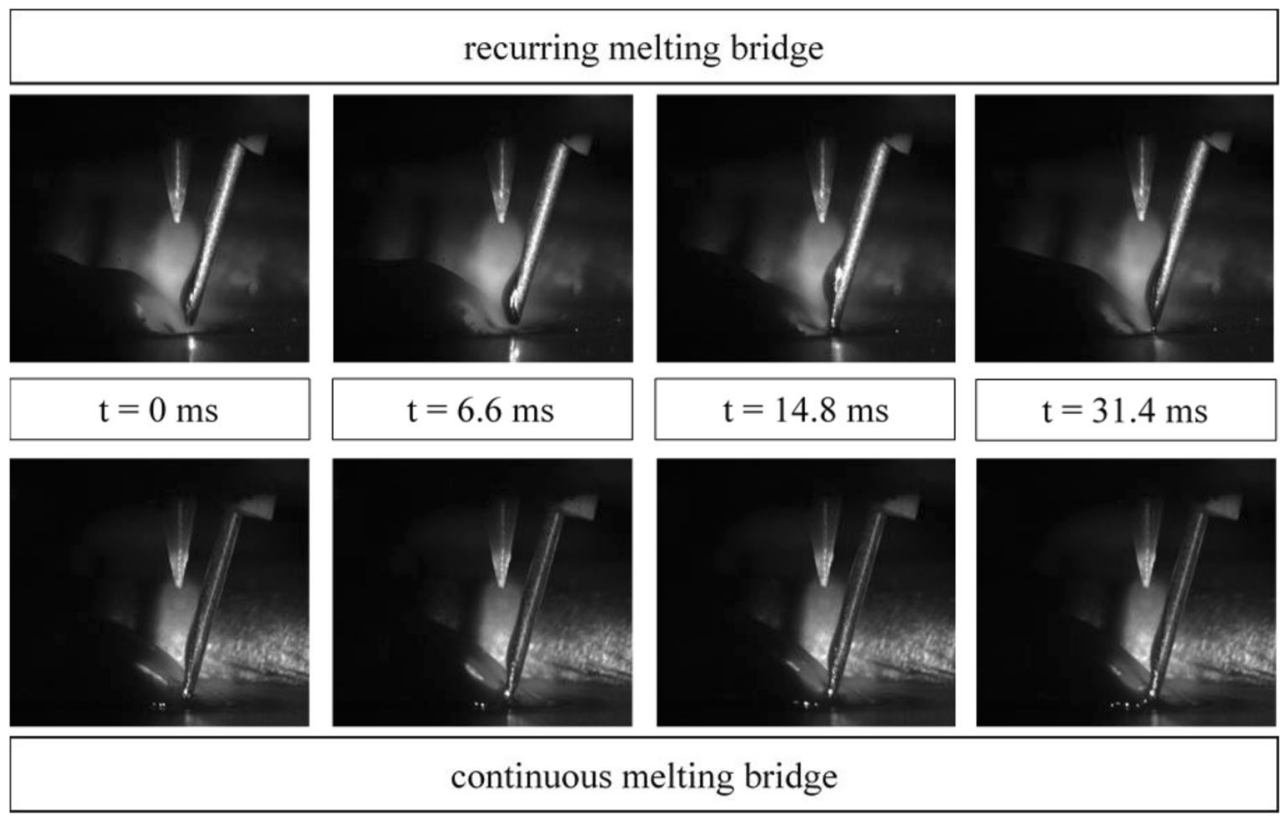


Fig. 8 Metal transfer for a wire feed rate $\mathrm{v}_{\mathrm{HW}}$ of $6 \mathrm{~m} / \mathrm{min}$ (left) and $8 \mathrm{~m} / \mathrm{min}$ (right)
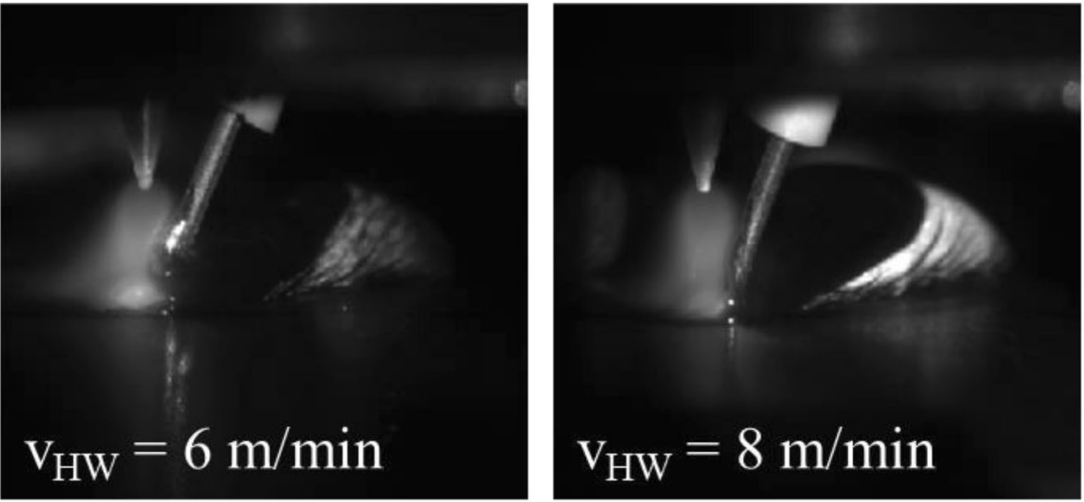

and decreased surface tension of the wire when leaving the preheating unit due to an increase in the hot-wire current.

From the performed internal and external bead analysis, it can be seen that the different types of metal transfer only have a minor influence on the bead properties; see Fig. 6 .

An increase of the hot-wire current results in an increase of the bead width, which can be related to an increasing temperature of the weld pool. This is due to the higher temperature of the wire when preheated with higher hot-wire currents, thus causing a decreasing surface tension of the melt and resulting in an improved wetting behaviour. A decrease of the bead height would to be expected. However, regarding the measured values of the bead height, this trend is not as clear, which is due to variations in the bead shape, mainly undercuts. This observation can be taken from the metallurgical examinations. From the examined parameters, no direct correlation can be determined regarding the penetration. In Fig. 7, the two types of metal transfer are shown to further characterize the different phenomena.

\subsection{Influence of the wire feed rate}

In this chapter, the influence of the wire feed rate on the metal transfer and the process behaviour is described. For

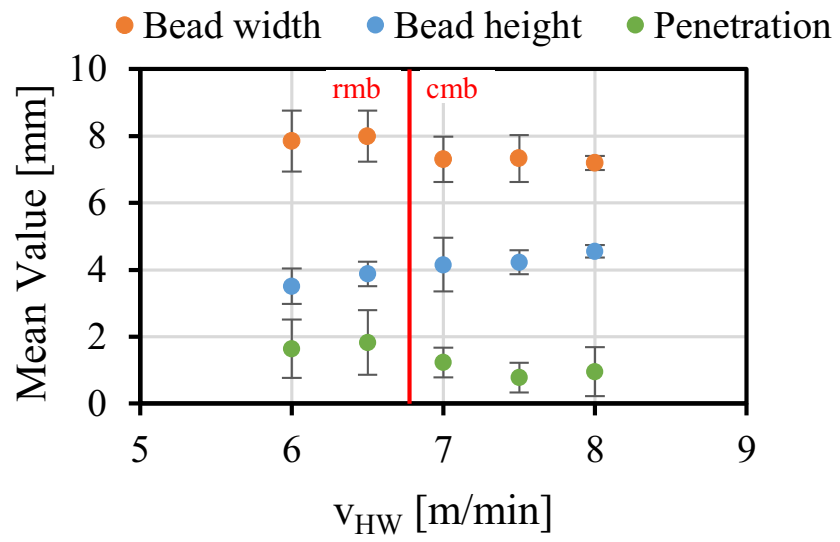

Fig. 9 Bead height, bead width and penetration for different wire feed rates $\mathrm{v}_{\mathrm{HW}}$ this purpose, process visualizations with a wire feed rate of $6 \mathrm{~m} / \mathrm{min}$ and $8 \mathrm{~m} / \mathrm{min}$ are shown in Fig. 8 .

The influence of the wire feed rate on the metal transfer is inverse to the influence of the hot-wire current (see 4.2.). At a wire feed rate of $6.0 \mathrm{~m} / \mathrm{min}$, a recurring melting bridge is formed. When increasing the wire feed rate, the metal transfer mode changes to a continuous melting bridge. If the wire feed rate is increased to $8 \mathrm{~m} / \mathrm{min}$, a faltering movement of the wire occurs. The reason for the described process behaviour can be a decreasing temperature of the wire when leaving the preheating unit as the wire feed rate increases. Using the measurement method developed by Spaniol et al. [24], hot-wire temperatures of $900 \mathrm{~K}$ for $6 \mathrm{~m} / \mathrm{min}, 870 \mathrm{~K}$ for $7 \mathrm{~m} / \mathrm{min}$ and $840 \mathrm{~K}$ for $8 \mathrm{~m} / \mathrm{min}$ were determined. These temperatures have to be seen as guidelines due to the changing of the preheating behaviour during the process.

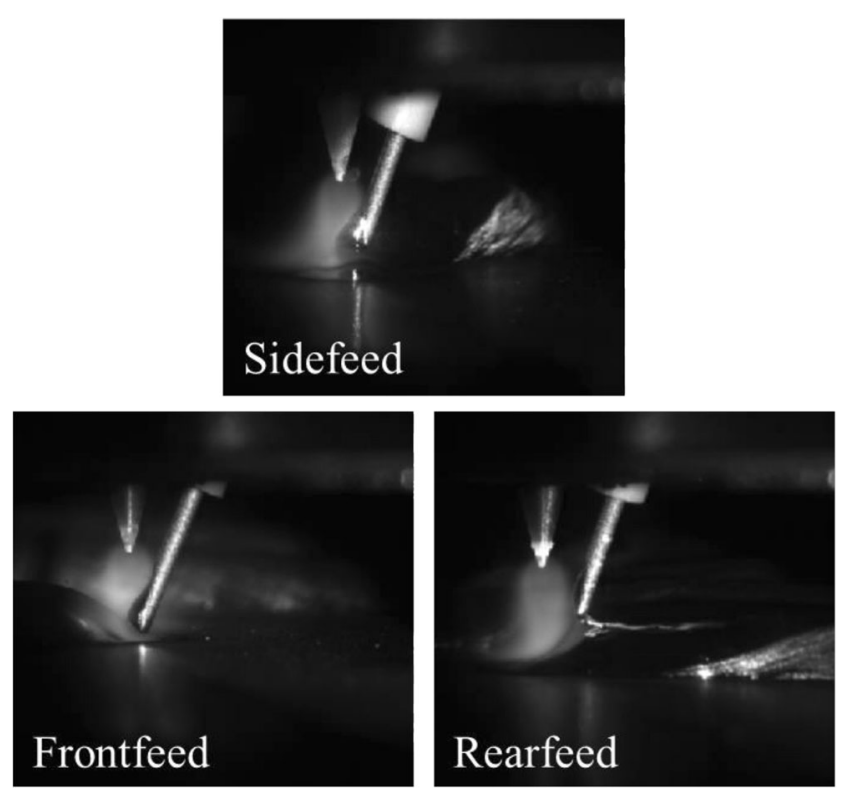

Fig. 10 Metal transfer for wire feed directions sidefeed (top), frontfeed (bottom left) and rearfeed (bottom right) 

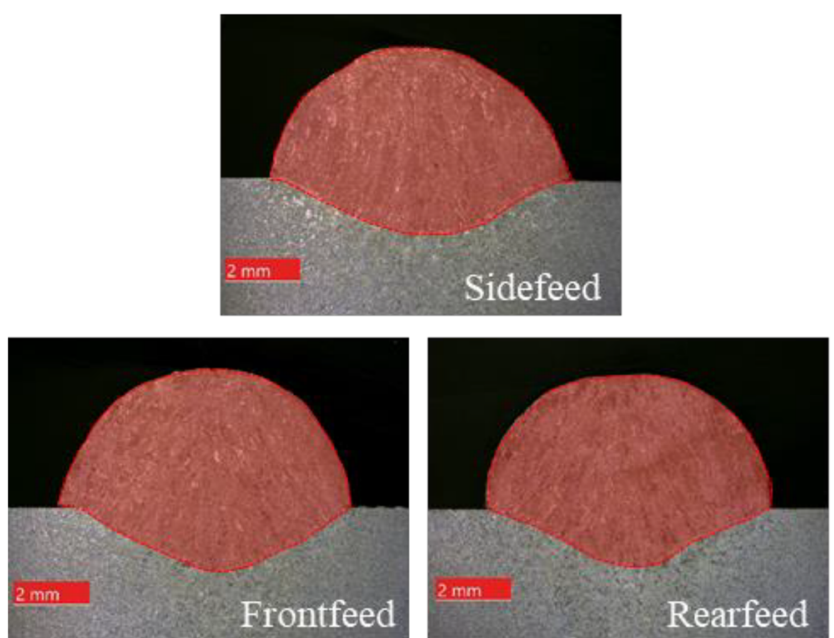

Fig. 11 Cross sections for wire feed directions sidefeed (top), frontfeed (bottom left) and rearfeed (bottom right)

Figure 9 illustrates the influence of the wire feed rate on the bead width, the bead height and the penetration. It is shown that with increased wire feed rates, the bead width as well as the penetration decrease slightly and the bead height increases. The described correlation may be caused by reduced temperatures in the melt pool and consequently increased viscosity of the melt with increasing wire feed rates.

\subsection{Influence of the wire feed direction}

Figure 10 illustrates the influence of the wire feed direction on the metal transfer.

The corresponding cross sections of the welds as well as the bead images are presented in Figs. 11 and 12.

Rea

It can be seen that the type of metal transfer greatly varies for the three different wire feed directions. As

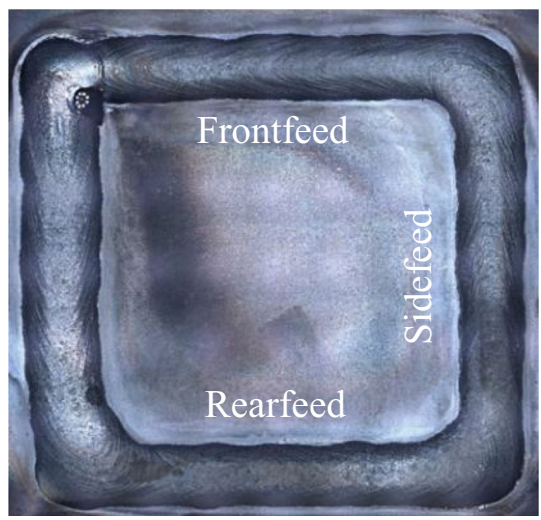

Fig. 12 Top view of the welds for wire feed directions frontfeed (top), sidefeed (right) and rearfeed (bottom)

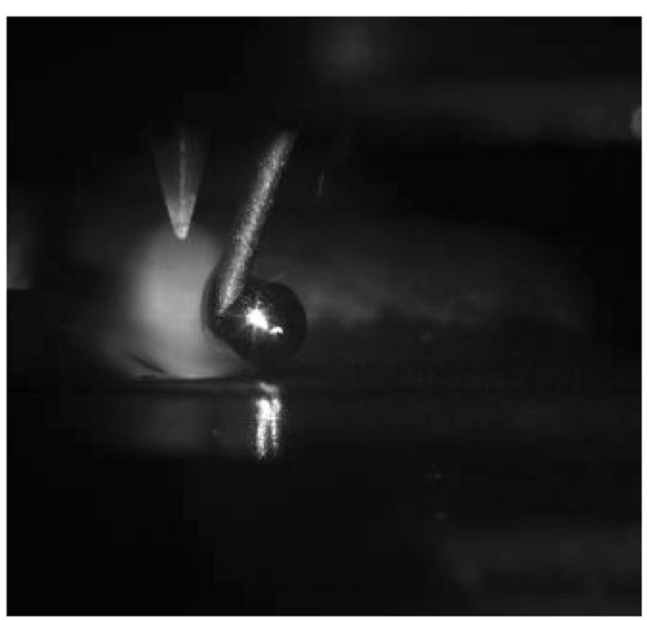

Fig. 13 Molten wire tip

already described in Section 4.1., molten material forms at the wire tip when the wire is fed from the side (sidefeed). A recurring melting bridge therefore occurs. When the wire is arranged in front of the arc (frontfeed), this behaviour occurs analogously. However, it should be noted that due to the greater distance between the wire tip and the melt pool, larger molten wire tips are formed (see Fig. 13).

Using the rearfeed, the wire is in continuous contact with the molten pool and is therefore melted continuously. With a shorter distance between the wire tip and the melt pool, a continuous melting bridge occurs. Although the metal transfer for the three directions of the wire feed varies greatly, the respective inner and outer bead geometries appear to be very similar (see Fig. 14).

The same behaviour can be concluded for the process stability as well as the appearance of the bead. Welding defects were not observed whilst performing the inner and outer bead analysis. Deviations can only be detected for the penetration.

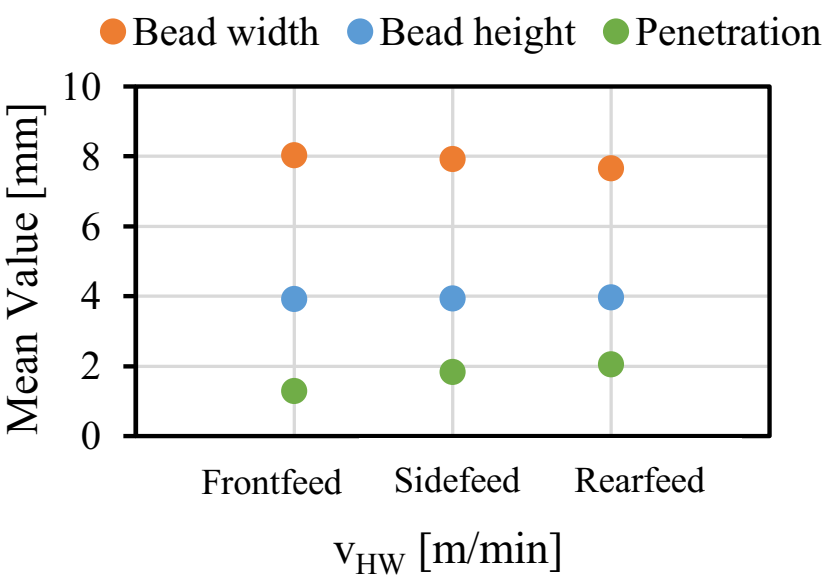

Fig. 14 Bead height, bead width and penetration for different wire feed directions 
Fig. 15 Metal transfer for wire feeding angles of $70^{\circ}$ (left) and $60^{\circ}$ (right)
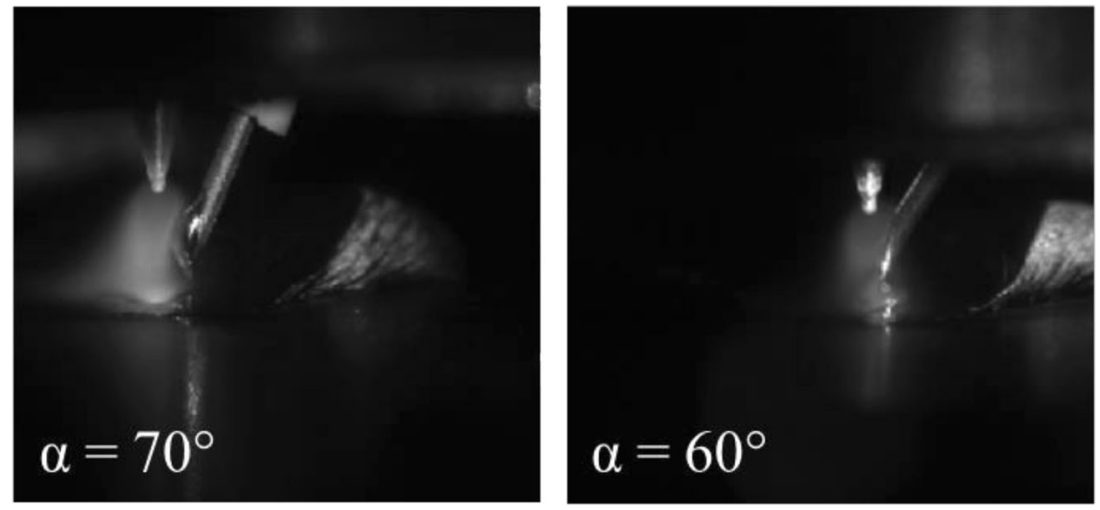

\subsection{Influence of the wire feeding angle}

As a result of the investigations, a significant difference in the material transition between the two examined wire feeding angles $\left(60^{\circ}\right.$ and $\left.70^{\circ}\right)$ was found; see Fig. 15 .

The main reason for the clear differences in the occurring types of metal transfer lies in the influence of the arc. At an inclination angle of $70^{\circ}$, the length of the wire within the arc is significantly greater than at an angle of $60^{\circ}$. This greater distance in the arc therefore increases the energy input from the arc into the wire.

Although a clear difference regarding the occurring metal transfer can be seen for the investigated wire feeding angles, the difference regarding outer and inner bead geometry is only marginal; see Fig. 16.

The change in the wire feeding angle has a clear influence on the process stability, which was also presented by Spaniol [23]. The process window for a $70^{\circ}$ inclination angle is significantly bigger than the process window for a $60^{\circ}$ angle.

- Bead width $70^{\circ} \bigcirc$ Bead height $70^{\circ} \odot$ Penetration $70^{\circ}$

- Bead width $60^{\circ} \diamond$ Bead height $60^{\circ} \bullet$ Penetration $60^{\circ}$

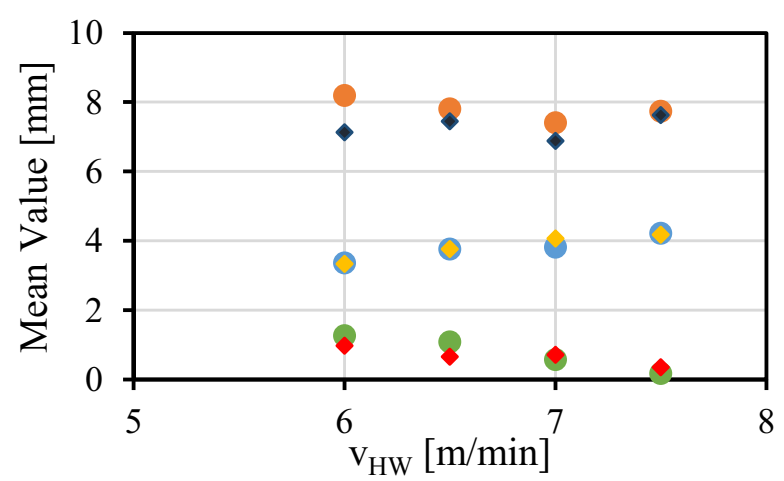

Fig. 16 Bead height, bead width and penetration for different wire feeding angles $\alpha$ and wire feed rates $\mathrm{v}_{\mathrm{HW}}$

\section{Conclusion}

In the context of this contribution, experimental investigations regarding a TIG hot-wire process with an indirect resistive preheating of the filler wire were carried out. As previous investigations of the process were limited to the analysis of the process stability and productivity, this contribution examined the impact of the process parameters on both the metal transfer and the resulting bead geometry. The presented results were derived from high-speed video data with synchronized recordings of the electrical data as well as metallographic examinations.

Based on the experimental investigations, two different metal transfer modes could be observed: a continuous melting bride and a recurring melting bridge. For the $\mathrm{cmb}$ transfer mode, the wire is in permanent contact with the weld pool resulting in a continuously transfer of molten material from the tip of the wire to the base material. In the second material transfer mode, the contact between wire and weld pool is temporarily interrupted. Due to the high surface tension of the melt, the material is not detached from the wire to the weld pool. The transfer only takes place when a contact between the filler wire and the weld pool is established. The melting bridge is then dissolved, and the wire tip is melted again. The temperature of the wire may be regarded as the main factor responsible for the occurring metal transfer modes, but further investigations have to be carried out in this respect. In addition, the analysis clearly reveals that the process parameters and thus the material transfer mode only have a small influence on the bead properties within the examined parameter range. The process can therefore be regarded as direction-independent, making it particularly suitable for the use in additive manufacturing. As for a preferred mode of metal transfer, it can be seen that with a continuous melting bridge, the weld seems to be more uniform and repeatable. A recurring melting bridge is on the other hand an indicator for a better process stability. Further investigations have to be performed to understand the influence of the metal transfer mode on the mechanical properties of the welds. 
Acknowledgements Open Access funding provided by Projekt DEAL.

Open Access This article is licensed under a Creative Commons Attribution 4.0 International License, which permits use, sharing, adaptation, distribution and reproduction in any medium or format, as long as you give appropriate credit to the original author(s) and the source, provide a link to the Creative Commons licence, and indicate if changes were made. The images or other third party material in this article are included in the article's Creative Commons licence, unless indicated otherwise in a credit line to the material. If material is not included in the article's Creative Commons licence and your intended use is not permitted by statutory regulation or exceeds the permitted use, you will need to obtain permission directly from the copyright holder. To view a copy of this licence, visit http://creativecommons.org/licenses/by/4.0/.

\section{References}

1. C. Caviezel, R. Grünwald, S. Ehrenberg-Silies, S. Kind, T. Jetzke, and M. Bovenschulte, 'Additive Fertigungsverfahren (3-DDruck)', p. 248, 2017

2. Liu L, Zhuang Z, Liu F, Zhu M (2013) Additive manufacturing of steel-bronze bimetal by shaped metal deposition: interface characteristics and tensile properties. Int J Adv Manuf Technol 69(9): 2131-2137. https://doi.org/10.1007/s00170-013-5191-7

3. Ding D, Pan Z, Cuiuri D, Li H (2015) Wire-feed additive manufacturing of metal components: technologies, developments and future interests. Int J Adv Manuf Technol 81(1):465-481. https://doi.org/10.1007/s00170-015-7077-3

4. Guo N, Leu MC (2013) Additive manufacturing: technology, applications and research needs. Front Mech Eng 8(3):215-243. https://doi.org/10.1007/s11465-013-0248-8

5. Saenger JF (1968) High deposition gas tungsten arc welding. Weld J 47(5):386-393

6. Manz AF, Saenger JF, Freeman ND, Stanchus FT (1969) 'Method for depositing metal with a tig arc', US3483354A

7. Hori K, Watanabe H, Myoga T, Kusano K (2004) Development of hot wire TIG welding methods using pulsed current to heat filler wire - research on pulse heated hot wire TIG welding processes. Weld Int 18(6):456-468. https://doi.org/10.1533/wint.2004.3281

8. Saenger JF, Manz AF (1982) High deposition gas tungsten-arc welding: (tig hot wire). Union Carbide Corporation, Linde Division

9. Shinozaki K (2006) Study on high speed welding with hot wire TIG welding methods using pulsed current to heat filler wire (Report2): 64. https://doi.org/10.14920/jwstaikai.2006f.0.64.0

10. Shinozaki K (2008) Development of ultra-high-speed GTA welding process using pulse-heated hot wire:107. https://doi.org/ 10.14920/jwstaikai.2008s.0.107.0
11. Shinozaki K et al (2009) Melting phenomenon during ultra-highspeed GTA welding method using pulse-heated hot-wire. Q J Jpn Weld Soc 27(2):22s-26s. https://doi.org/10.2207/qjjws.27.22s

12. Shinozaki K, Yamamoto M, Mitsuhata K, Nagashima T, Kanazawa T, Arashin H (2011) Bead formation and wire temperature distribution during ultra-high-speed GTA welding using pulse-heated hot-wire. Weld World 55(3):12-18. https://doi.org/10.1007/ BF03321281

13. Santangelo M, Silwal B, Purdy A (2016) Vibration assisted robotic hotwire gas tungsten arc welding (Gtaw) for additive manufacturing of large metallic parts

14. Henon KB (2015) Advances in automatic hot wire GTAW (TIG) welding. Arc Machines, Inc., ,Case Study, Pacoima

15. Chen J, Lu Y, Li XR, Zhang YM (Oct. 2012) Gas tungsten arc welding using an arcing wire. Weld J 91:261s-269s

16. Chen S, Zhang S, Huang N, Zhang P, Han J (2016) Droplet transfer in arcing-wire GTAW. J Manuf Process 23:149-156. https://doi. org/10.1016/j.jmapro.2016.05.014

17. Lv SX, Tian XB, Wang HT, Yang SQ (2007) Arc heating hot wire assisted arc welding technique for low resistance welding wire. Sci Technol Weld Join 12(5):431-435. https://doi.org/10.1179/ $174329307 X 213828$

18. McAninch MD (2007) Induction heated, hot wire welding

19. Stol I (1989) 'Method and apparatus for controlling the temperature of continuously fed wires', CA1253580A

20. Spaniol E, Ungethuem T, Trautmann M, Andrusch K, Hertel M, Fuessel U (2018) Development of a novel TIG hot-wire process for wire and arc additive manufacturing. In: IIW 2018, IIW Doc. 2121548-18 /XII-2398-18, Bali, Indonesia, p 15

21. DIN EN ISO 5817 (2014) Schweißen - Schmelzschweißverbindungen an Stahl, Nickel, Titan und deren Legierungen (ohne Strahlschweißen) - Bewertungsgruppen von Unregelmäßigkeiten (ISO 5817:2014); Deutsche Fassung

22. Siewert E, Schein J, Forster G (2013) Determination of enthalpy, temperature, surface tension and geometry of the material transfer in PGMAW for the system argon-iron. J Phys D Appl Phys 46(22): 224008. https://doi.org/10.1088/0022-3727/46/22/224008

23. Spaniol E, Ungethuem T, Trautmann M, Hertel M, Füssel U (2019) Influence of the wire feeding angle on the process behaviour of a TIG hot wire process with indirect resistive preheating. In: IIW Intermediate Meeting, XII-2422-19, Greifswald, Germany, p 22

24. Spaniol E, Lohse M, Hertel M, Füssel U (2019) Methods for the determination of temperature dependent material properties of filler metals for hot-wire welding. Presented at the visual-JW and WSE, Osaka, Japan

Publisher's note Springer Nature remains neutral with regard to jurisdictional claims in published maps and institutional affiliations. 